\title{
EXPERIMENTAL NESTBOXES FOR BLUEBIRDS: AN UPDATE
}

\author{
RONALD A. BITTNER, Box 97, Abernethy, SK. SOA OAO
}

I started experimenting with Mountain Bluebird nestbox designs in 1987. The number of kinds grew to 10 by 1990 , and to 13 by 1994 . Some are standard nestboxes with varying dimensions; others are test boxes of several designs with two entrances. I now have 72 boxes of 13 kinds. Previously I showed that bluebirds prefer the test boxes and Tree Swallows the standard boxes.

This article gives the results up to 1995 for the two most successful kinds of test boxes. When these boxes are paired with standard boxes with predator guards, bluebirds have favoured the test boxes by more than a factor of four. Because of serious raccoon predation in 1989 and 1990, my objectives were expanded to develop a box that was: raccoon-resistant without the use of special mounting poles or other predator guards; similar in size and weight to standard nestboxes for easy mounting on fence posts; and relatively easy to build.

The two test box types (see Fig. 1) have double entrances. Plan A uses sloping passages to prevent raccoons reaching into the nest. The entrances are slots 1.25" X 2.5". Plan B uses a shelf below the entrance holes for predator protection. The circular entrances are $1.5^{\mathrm{I}}$ in diameter. Earlier versions of this type used slot entrances and external guards similar to Plan $\mathrm{A}$. The change to round holes without external guards simplified the plan while maintaining adequate predator protection. Both types have a floor size $5.5^{\prime \prime} \times 5.0^{\prime \prime}$. Depth from the top of the baffle to the floor is about 7 ".

My standard boxes have a $1.5^{\mathrm{\prime \prime}} \mathrm{di}-$ ameter circular entrance. Each has a raccoon guard, an interior baffle below the entrance. Some also have an exterior guard, a small block of wood with a $1.75^{\prime \prime}$ hole, thickening the entrance wall. The floor size is about $5^{\prime \prime} \times 5^{\prime \prime}$; depths range from 6-7".

Boxes are mounted on fence posts bordering grazed pasture with some scattered trees - good bluebird habitat. At each site, a standard box and a test box are mounted about 10 yds apart, the distance between sites being about 250 yds. To avoid biasing the data, each type has boxes at varying distances from trees, ranging from 50 yds to 0.5 miles. Boxes are monitored regularly to determine nesting species and nesting success.

Table 1 gives the occupancy by species for the two test boxes and the adjoining standard boxes. An occupied box is defined here as one in which a nest is built and at least one egg is laid. The "Other/Empty" category includes boxes used by other species and boxes used by bluebirds or swallows where the nesting did not advance to the egg-laying stage. Note that the sum of the other three categories can exceed the number of box-years. This is because bluebirds and swallows sometimes nest in the same box in one year, usually with the swallows following the bluebirds.

The table shows the strong preferences. Of the 109 boxes occupied by 


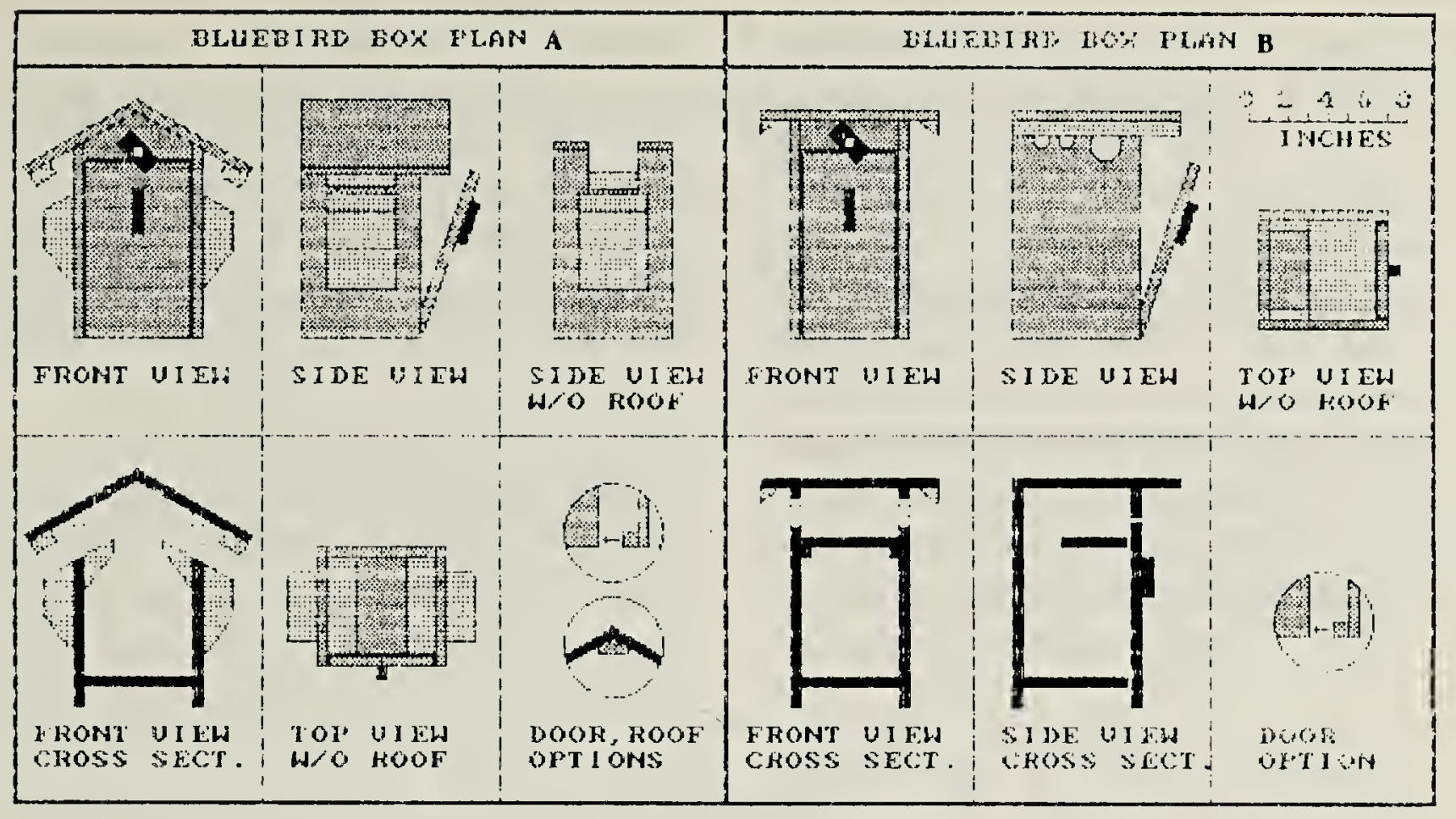

Figure 1. Experimental double-entrance bluebird nestboxes.

bluebirds at the Plan A sites, 90 were test boxes and 19 were standard boxes. Of the 58 boxes occupied by bluebirds at the Plan B sites, 47 were test boxes and 11 were standard boxes. At both types of site, swallows chose the standard boxes by an even wider margin. Some of the test box data came from earlier versions of the latest plans.

An interesting aspect of the swallow data is that there are two factors involved in the occupancy rate. In addition to the swallows' preference for the standard boxes, there are more standard boxes available when the swallows nest. This is because bluebirds usually choose the test boxes, leaving the standard boxes for the later-nesting swallows.
Discussion Swallows spend considerable time looking out their entrance hole. With two entrances, they cannot guard both at once, hence they may dislike the double-entrance boxes. Bluebirds may prefer the test boxes because there is less competition with swallows. This is probably a minor point because bluebirds usually nest first. Bluebirds also may prefer a more open box. Note that they occasionally nest on a ledge on the interior or exterior of a building. In addition, bluebirds may prefer an entrance which is partly concealed by an overhanging roof, or one where the bird enters at an upward angle. Bluebirds occasionally fly upwards to reach a nest. For example, they have been known to nest in such places as the outlet of a grain

\begin{tabular}{|c|c|c|c|c|}
\hline Type of Box & Box-years & Bluebirds & Swallows & Other/Empty \\
\hline Plan A Experimental Boxes & 119 & 90 & 11 & 19 \\
\hline Adjoining Standard Boxes & 119 & 19 & 100 & 5 \\
\hline Plan B Experimental Boxes & 119 & 47 & 9 & 18 \\
\hline Adjoining Standard Boxes & 119 & 11 & 49 & 14 \\
\hline
\end{tabular}


auger in a farm yard. The test boxes are easy to enter and safe to inspect. A bird is not required to squeeze through a long, tight passage before it can inspect the box, as one type of predator guard requires. They may view the boxes as being more predator-resistant. The nest cannot be seen by a predator unless it actually enters the box. However, this is also true for most of the standard boxes used in this experiment, since they are equipped with predator guards.
Acknowledgements I thank Bill Anaka of Canora, SK for building and testing boxes based on these designs. He supplied much of the data in Table 1. For their interest in this project, I also thank Roxanne Brown of Assiniboia, SK, Don Stiles of Calgary, $A B$, and Myrna Pearman of Ellis Bird Farm, Lacombe, AB.

1. BITTNER, R.A. 1993. Bluebird nestboxes: unusual designs. Blue Jay $51: 49-51$.

I was intrigued by the circumstance that social insects, the group on which I have spent most of my life, are among the most abundant of all organisms. And among the social insects, the dominant subgroup is the ants. They range 20,000 or more species strong from the Arctic Circle to the tip of South America. In the Amazon rain forest they compose more than 10 percent of the biomass of all animals. This means that if you were to collect, dry out, and weigh every animal in a piece of forest, from monkeys and birds down to mites and roundworms, at least 10 percent would consist of these insects alone. Ants make up almost half of the insect biomass overall and 70 percent of the individual insects found in the treetops. They are only slightly less abundant in grasslands, deserts, and temperate forests throughout the rest of the world. Wilson, E.O. 1992. The diversity of life. W.W. Norton and Company, New York. 424 pp. 